\title{
Muscle fibre ontogenesis in farm animal species
}

\author{
Brigitte PICARD $^{\mathrm{a} *}$, Louis LEFAUCHEUR ${ }^{\mathrm{b}}$, Cécile BERRI $^{\mathrm{c}}$, \\ Michel J. DuCLOS ${ }^{\mathrm{c}}$

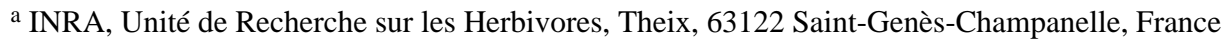 \\ b INRA, Unité Mixte de Recherches sur le Veau et le Porc, 35590 Saint-Gilles, France \\ c INRA, Station de Recherches Avicoles, 37380 Nouzilly, France
}

\begin{abstract}
In farm animals (bovine, ovine, swine, rabbit and poultry), muscle fibre characteristics play a key role in meat quality. The present review summarises the knowledge on muscle fibre characteristics and ontogenesis in these species. Myofibre ontogenesis begins very early during embryonic life, with the appearance of two or three successive waves of myoblasts which constitute the origin of the different types of muscle fibres. In small animals (rodents and poultry), a primary and a secondary generation of fibres arise respectively during the embryonic and foetal stages of development. In the largest species (bovines, sheep, pigs) a third generation arises in the late foetal or early postnatal period. Following these two or three waves of myogenesis, the total number of fibres is fixed. This occurs during foetal life (bovines, ovines, pigs and poultry) or during the first postnatal month in rabbits. Contractile and metabolic differentiation proceed by steps in parallel to myogenesis and are partially linked to each other. In bovines and ovines, the main events occur during foetal life, whereas they occur soon after birth in the pig, poultry and rabbit, but some plasticity remains later in life in all species. This comparative survey shows that the cellular processes of differentiation are comparable between species, while their timing is usually species specific.
\end{abstract}

myogenesis / myofibre / myosin / species

\section{INTRODUCTION}

In farm animals, a better control of meat quality is of major importance for producers and retailers in order to satisfy the consumer's requirement for a consistently good

* Correspondence and reprints

E-mail: picard@clermont.inra.fr product. Several studies dealing with the biological mechanisms involved in the determination of the meat sensory quality suggest that the production factors (age, breed, feeding...) exert an effect on meat quality by altering the biological characteristics of 
the muscle tissue (collagen, fibres, lipids, enzymes...) and those of the muscle fibres in particular. Muscle fibre characteristics are involved in meat tenderness and flavour in different species [43]. The rate and extent of post-mortem $\mathrm{pH}$ decline is higher in fasttwitch glycolytic muscles with higher glycogen. This type of muscle also exhibits faster post-mortem ageing [55]. Oxidative muscles generally contain higher levels of lipids in favour of a better flavour. In sheep, a direct positive relationship between flavour and the percentage of oxidative fibres has been shown [95]. A negative correlation between fibre cross sectional area and tenderness has been reported in pigs and bovines $[67,69]$. Thus, meeting the challenge of optimising the efficiency of muscle growth and meat quality requires a thorough understanding of the processes involved in muscle fibre development and diversification in meat producing species.

The aim of this review was to describe the classification of the different types of fibres and to compare their ontogenesis in the different meat producing species (i.e. bovines, ovines, pigs, poultry, rabbits). The mechanisms of regulation which are numerous and complex will not be described; for review [77], see Buckingham et al. [11].

\section{MYOFIBRE CHARACTERISTICS}

\subsection{Myofibre typing}

The skeletal muscle fibres represent a heterogeneous population differing in their energy metabolism, contractile properties and colour. Various methods based on histochemical approaches have been proposed to classify the different fibre types. They were originally classified on the basis of their major metabolic activities, such as oxidative or glycolytic [22]. They have also been distinguished on the basis of their contractile properties evaluated by their myofibrillar actomyosin adenosine triphosphatase (mATPase) activity [27] measured following alkaline or acid pre-incubation (Figs. 1A and 1B). The mATPase activity of type I slowtwitch fibres is inhibited after alkaline preincubation, while that of type II fast-twitch fibres is inhibited after acid pre-incubation (Fig. 1A). Three subclasses can be identified within type II fibres in humans [10] by pre-incubating muscle sections at two different acid $\mathrm{pH}$ (4.3 and 4.9): the IIA fibres exhibit an mATPase activity which is inhibited after pre-incubation at $\mathrm{pH}<4.9$, while that of the IIB fibres is inhibited at $\mathrm{pH}<4.3$ and that of the IIC fibres is partially resistant at this last $\mathrm{pH}$. However, the conditions of $\mathrm{pH}$ pre-incubation must be defined for each species and ages. In birds, type III fibres (slow tonic and multi innervated fibres) can also be distinguished. Combining metabolic enzyme-based and mATPase-based histochemical methods, Barnard et al. [6], and Peter et al. [61] distinguished three types of fibres (Fig. 1C) : slow-twitch oxidative (SO), fast-twitch oxido-glycolytic (FOG) and fasttwitch glycolytic (FG). Similarly, Ashmore and Doerr [1] by combining the measure of $\mathrm{mATPase}$ activity and the activity of SDH, an enzyme of the metabolic pathway, also described three types of fibres: $\beta \mathrm{R}$, ATPase acido-resistant and oxidative metabolism; $\alpha \mathrm{R}$, ATPase acido-labile and oxido-glycolytic metabolism; $\alpha \mathrm{W}$, ATPase acidolabile and glycolytic metabolism (Tab. I). These classifications are the most commonly used. However, further subtypes of fibres can be delineated (cf. review of Staron and Pette [84]), which suggests differences in the molecular composition of myosin within a class.

\subsection{Myosin heavy chain isoforms}

Myosin is the predominant protein in skeletal muscle (about $1 / 3$ of the total muscle proteins), and it makes up the largest portion of the contractile apparatus of muscle fibres. This hexameric protein consists in four light chains (MLC) and two heavy chains (MHC), each of which exists in 


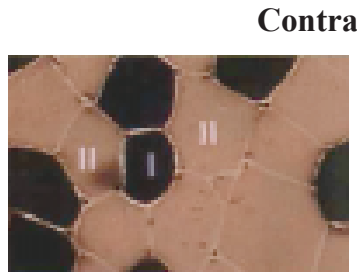

(A) Acidic ATPase

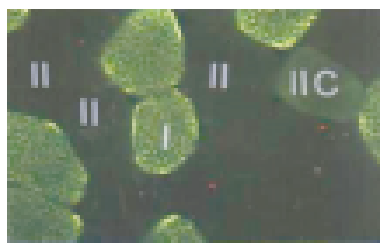

Antibody I

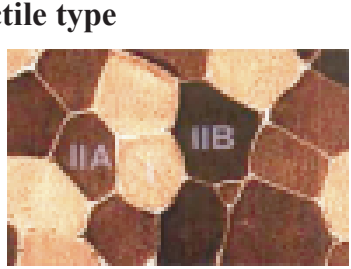

(B) Alkaline ATPase

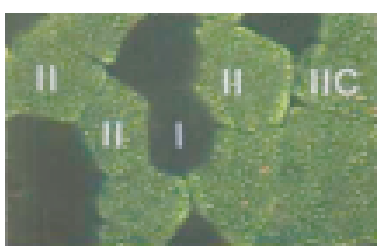

Antibody II
Metabolic type

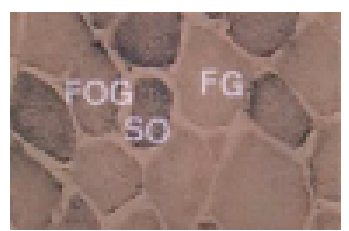

(C) SDH

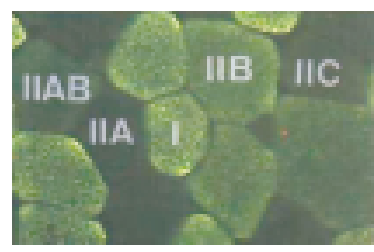

Antibody I and IIb

Figure 1. Classification of muscle fibres (A) Guth and Samaha [33] (B) Brooke and Kaiser [10] (C) Peter et al. [61]; (d) use of antibodies. SDH: Succinate dehydrogenase. Antibody I: anti slow MHC. Antibody II: anti fast MHCs. Antibody I and IIb recognises both MHC I and MHC Ilb/IIx.

Table I. Characteristics of the different fibre types (Bacou and Vigneron [2]). (1) Nomenclature of Brooke and Kaiser [10], (2) nomenclature of Ashmore and Doerr [1], (3) nomenclature of Peter et al. [61].

\begin{tabular}{|c|c|c|c|c|}
\hline & \multirow[b]{2}{*}{$\begin{array}{l}\text { (1) } \\
\text { (2) } \\
\text { (3) }\end{array}$} & \multicolumn{3}{|c|}{ Fibre types } \\
\hline & & $\begin{array}{c}\mathrm{I} \\
\beta \mathrm{R}(\mathrm{red}) \\
\mathrm{SO} \\
\text { (slow oxidative) }\end{array}$ & $\begin{array}{c}\text { IIA } \\
\alpha R \text { (red) } \\
\text { FOG } \\
\text { (fast oxido- } \\
\text { glycolytic) }\end{array}$ & $\begin{array}{c}\text { IIB } \\
\alpha \mathrm{W} \text { (white) } \\
\text { FG } \\
\text { (fast glycolytic) }\end{array}$ \\
\hline \multicolumn{5}{|l|}{ Physiology } \\
\hline Motrice unit & & $\mathrm{S}$ & FR & FF \\
\hline Speed of contraction & & Slow & Fast & Fast \\
\hline Fatigue resistance & & +++ & ++ & + \\
\hline \multicolumn{5}{|l|}{ Morphology } \\
\hline Colour & & Red & Red & White \\
\hline Myoglobine & & +++ & +++ & + \\
\hline Nomber of mitochondria & & +++ & +++ & + \\
\hline Sectional area & & + & +++ & +++ \\
\hline \multicolumn{5}{|l|}{ Metabolites } \\
\hline Glycogen & & + & +++ & +++ \\
\hline Lipides & & +++ & +++ & + \\
\hline \multicolumn{5}{|l|}{ Enzymatic properties } \\
\hline Myosin ATPase & & + & +++ & +++ \\
\hline Glycolytic enzymes & & + & ++ & +++ \\
\hline Oxidative enzymes & & +++ & ++ & + \\
\hline
\end{tabular}


numerous isoforms and can combine differently within a muscle fibre or even within a single myosin filament. The major MHC isoforms determine the contractile properties of a fibre. The diversity of these isoforms is due to their specific actin-activated and $\mathrm{Ca}^{2+}$-stimulated ATPase activities which reside in the head region of the heavy chain [34]. In mammals, slow twitch fibres contain the slow "MHC I" which corresponds to the cardiac beta myosin heavy chain. Another slow isoform "ICton" is also present in extraocular muscles, tensor tympani muscle and intrafusal fibres (see review in [84]). It corresponds to the MHC isoform associated with slow tonic fibres in the bird ALD muscle. In birds, there are at least 4 distinct slow MHC genes (see review in [4]). Recently, Hughes et al. [40] showed that at least 3 isoforms of slow twitch MHC could be distinguished in human and rat skeletal muscle based on the use of epitope specific monoclonal antibodies and that their expression was temporally distinct during early gestation. Alpha cardiac MHC is also detected in the skeletal muscle during foetal life in bovines [62] or early postnatal development in piglets $[46,47]$ and in special adult muscles such as the human masseter [7, 60].

Initially, in mammalian species, fast "MHCIIa" and "IIb" were reported to be expressed in type IIA and IIB fibres, respectively. However, an additional fast MHC called "IId" or "IIx" was identified, first in small animals [5, 78, 94], then in humans [81], pigs [48] and bovines [92]. It was shown to be the product of a specific gene, different from the genes coding IIa and IIb MHC [19, 81]. It is expressed in fibres called IIX which cannot be distinguished from the type IIB fibres by conventional histochemical techniques. They appear to be intermediate between the type IIA and IIB fibres with respect to their oxidative metabolism, resistance to fatigue and maximum velocity of shortening [81]. Initially, IIb MHC, the fastest isoform, was thought to be expressed only in small species in accordance with their fast movements. However, recent data on the pig muscle have shown that all three fast MHC isoforms are expressed in this species (Fig. 2). In bovine muscles, only two different types of fast fibres can be detected by histochemical techniques,
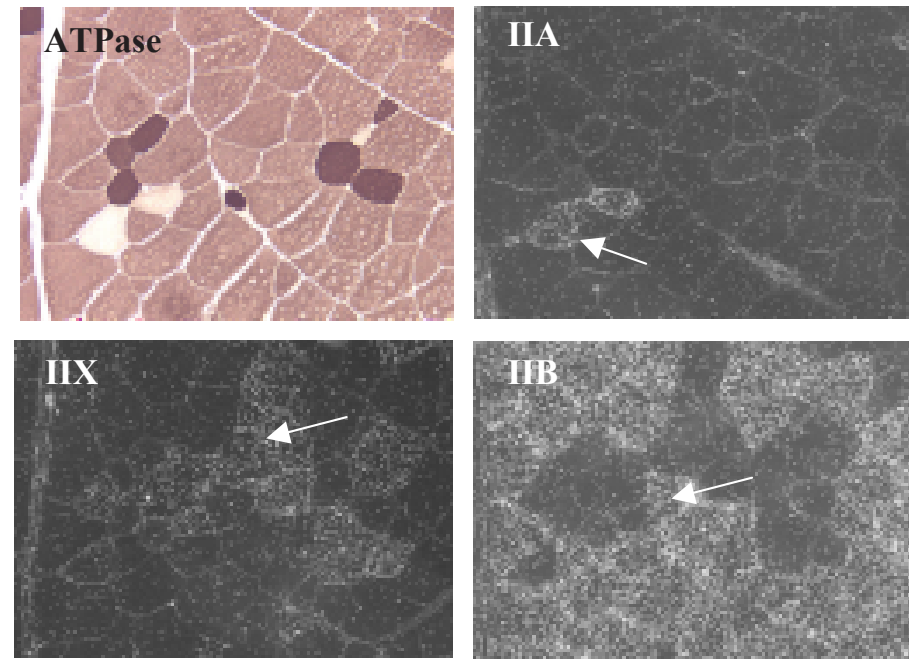

Figure 2. MHC in situ hybridisation in the pig longissimus muscle (100 kg BW), Lefaucheur et al. [48]. The three fast MHCs are observed in pig muscle. 
whereas 3 fast MHC isoforms were revealed by electrophoretic separation (Picard, data not published). This suggests that the three fast isoforms also exist in this species, but we were unable to distinguish between IIX and IIB fibres. Two other specific fast MHC have been detected in super-fast contracting fibres of extraocular muscles "MHC II eom" and in muscles derived from the first branchial arch "MHC IIm" [84]. Two developmental MHC are expressed at specific stages during development: embryonic MHC "MHC emb" and foetal MHC "MHC foet" also called neonatal MHC "MHC neo". These developmental MHC usually disappear in adult muscles, except in particular muscles such as the extraocular muscle [98], masseter [17] and intrafusal fibres [51]. In avian species, at least seven fast MHC genes have been identified (see [4] for a review) which cannot be unambiguously assigned to the different subtypes of fast fibres. Indeed, depending on the muscle, fast fibres of adult muscles can express one of the three embryonic MHC genes, the neonatal or the adult fast MHC gene.

The different MHC are the product of a multigene family, each gene coding a distinct isoform. Ten different MHC genes have been identified in mammals and more than 30 in birds. By contrast, only a single MHC gene was identified in Drosophila melanogaster where the diversity of MHC isoforms results from alternative splicing (see review in [3]). The organisation of the MHC genes is highly conserved, but there is more similarity between different fast isoforms or between different slow isoforms from different species than there is between fast and slow isoforms in one species. This is likely the result of gene conversion-like events within each gene family. It is consistent with the observation that the fast and slow MHC genes are arranged in two clusters on different chromosomes [49, 80, 96, 97]. In mammals, the cardiac alpha-MHC gene is closely linked to the beta/slow - MHC gene, on chromosome 14 in both humans and mice, and on chromosome 7 in the pig. The emb, IIa, IIx, IIb, neo, and extraocular MHC are localised in this order in another cluster on chromosome 11 in the mouse, 17 in humans and 12 in the pig. A similar organisation exists in the chicken, with seven fast MHC genes clustered on a micro-chromosome, and at least three of the four slow MHC genes closely linked on another chromosome (see review in [4]). But it seems that the evolution of MHC genes has been independent in birds and mammals [56].

\subsection{Myofibre diversity}

Muscle fibres can express one or a combination of more than one MHC. Examples of this can be found in humans [42], bovines [65], rats [91], and horses [70]. These hybrid fibres contain at least two MHC isoforms and can be designated according to the MHC present and their ratio, as IIBX (MHC IIb > MHC IIx), IIXB (MHC IIx > MHC IIb), IIXA (MHC IIx > MHC IIa), and IIAX (MHC IIa > MHC IIx). Fibres containing fast MHC IIa and slow MHC I are called C fibres, or type IIC (MHC IIa > MHC I) and type IC (MHC IIa < MHC I) [34]. Schiaffino and Reggiani [79] also described IIA/IIX fibres, and also observed that different isoforms can be expressed simultaneously in some muscle fibres during foetal life. In rats, Termin et al. [93] reported that type IIC fibres may contain a mixture of MHC I, MHC IIa and MHC neo in various proportions according to age. Up to four $\mathrm{MHC}$ isoforms have been found in a single fibre (I, IIa, IIx, IIb) under drastic conditions of induced conversion between fibre types [94]. It is now well documented that these hybrid fibres result from the transition of MHC expression following an obligatory pathway, i.e. I $\rightleftarrows \mathrm{IIa} \rightleftarrows \mathrm{IIx} \rightleftarrows \mathrm{IIb}$ illustrating the large plasticity of muscle tissue. Monoclonal antibodies specific for the different MHCs are essential tools to accurately classify these fibres (Fig. 1D).

The different fibres differ in MHC composition but also in size. An inverse 


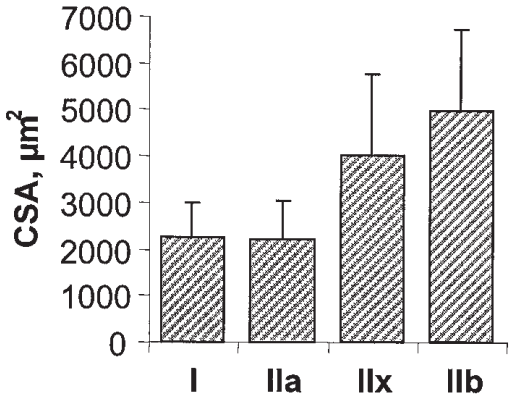

Figure 3. Cross sectional area (CSA) of myofibres in the pig longissimus muscle at $100 \mathrm{~kg} \mathrm{BW}$ (Lefaucheur, unpublished).

correlation generally exists between fibre diameter and the oxidative metabolism to facilitate the diffusion of oxygen to the mitochondria. In the different adult mammalian species, IIB fibres are the largest, I and IIA fibres the smallest, whereas IIX fibres exhibit an intermediate size (Fig. 3) consistent with their intermediate metabolism.
Depending on the maturity of the species, myofibre characteristics are determined during the foetal or perinatal periods.

\section{MYOGENESIS}

\subsection{Ontogenesis of myofibres}

Muscle fibres are issued from myogenic precursor cells called myoblasts which proliferate, then fuse to form myotubes, finally differentiating into muscle fibres (Fig. 4). The different steps of myogenesis have been described in birds and mammals. Myoblasts originate in the embryo from the mesoderm (Fig. 5), more precisely from the dermomyotome, which is part of segmented structures called somites [87]. The dorso-medial part of the dermomyotome gives rise to the paravertebral and limb muscles, while its ventrolateral part gives rise to the thoracic muscles. Craniofascial muscles come from the

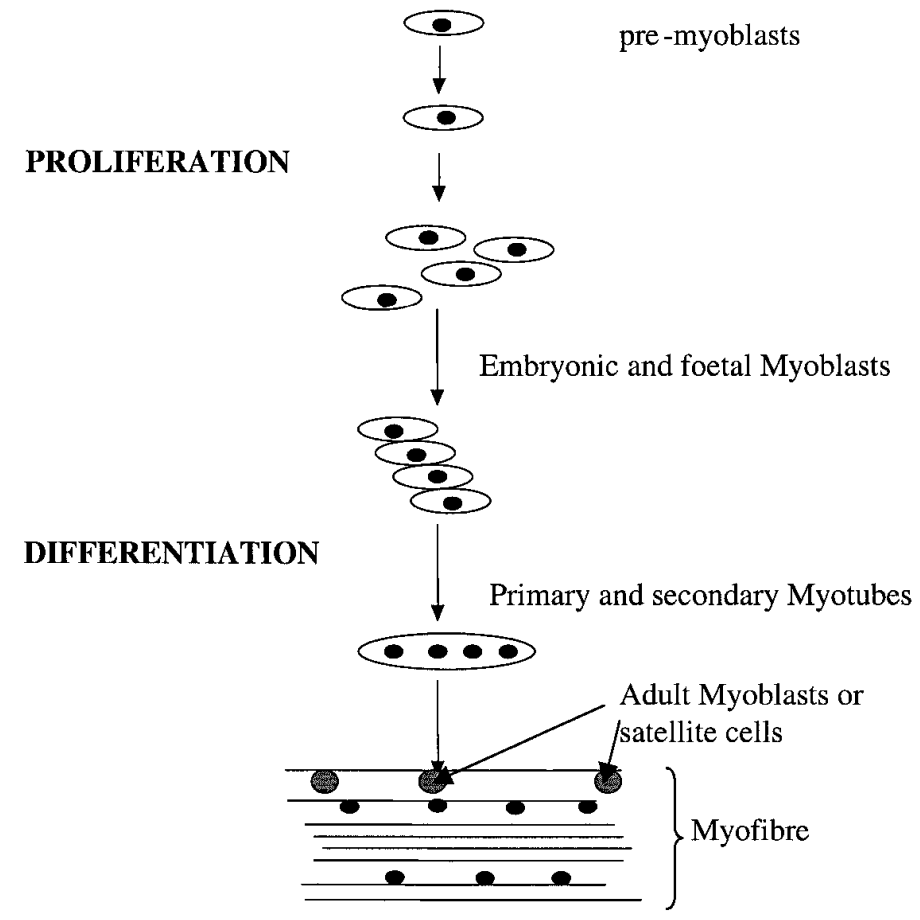

Figure 4. The different stages of myofibres formation. 
(a)

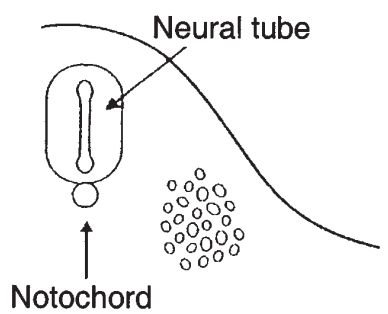

(b)

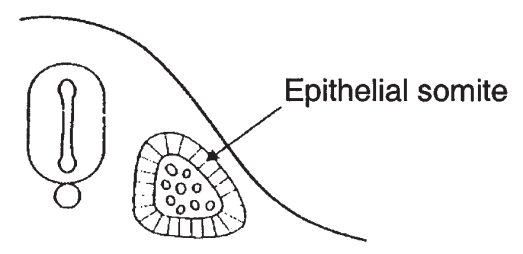

(c)

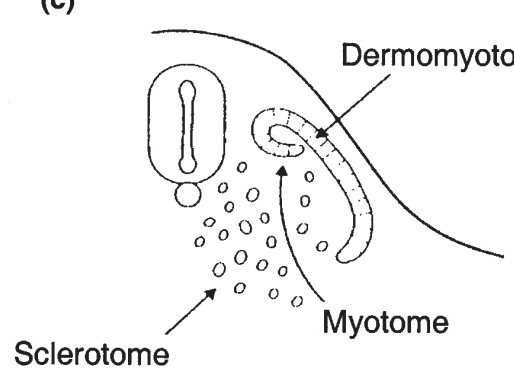

(d)

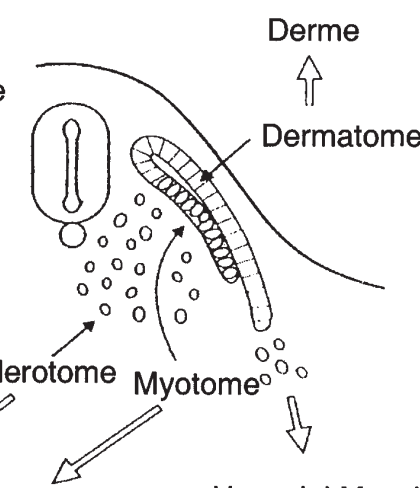

Epaxial

Hypaxial Muscles

Muscles

Limb Muscles

Figure 5. Origin and formation of muscle in vertebrates. (a) Somites formation. (b) Epithelial structure of a somite. (c) Differentiation of somites. (d) Differentiation of dermatome, myotome and sclerotom.

rostro-occipital and cephalic somites (see review in [82]). Undifferentiated myogenic cells migrate from the somites under the control of factors produced by the neural tube and notochord [82] and subsequently differentiate to form individual muscles. During their migration along the notochord, myogenic cells or "presumed myoblasts" proliferate, then leave the cell cycle, start to synthesise myofibrillar proteins and prepare their fusion (see reviews in [76] and [82]). The fusion process implies the recognition and alignment of adjacent myoblasts, the formation of gap junctions, the fusion of membranes and then of cytoplasms, together with numerous biochemical modifications. Myoblasts with distinct properties have been isolated at different stages of development and have been named somitic, embryonic, foetal and adult (or satellite) myoblasts [36, 39, 89].

\subsection{Different generations of myotubes}

During development, myotube formation occurs in two or three temporally distinct phases. The first wave of myotubes comes from embryonic myoblasts, the second from foetal myoblasts (Fig. 4) and they respectively give rise to the primary and secondary muscle fibres [28]. In birds, the majority of primary fibres express both fast and slow isoforms when they first appear, but the expression of a specific developmental slow MHC isoform (slow MHC III) specifies the future slow fibres (see review in [88]). At this stage, three distinct types of myoblasts 
can be isolated which give rise in vitro to fast, fast/slow or slow myotubes, respectively [88], suggesting that myoblasts are already committed to distinct lineages. The secondary fibres first express fast or fast and slow isoforms and the corresponding types of myoblasts can be isolated at this stage [88]. In all species, the myotubes of the primary generation account for a limited proportion of the future fibres, while those of the secondary generation which use them as a scaffold [82] build a much larger population [54, 82, 83] (Fig. 6). The number of secondary fibres around each primary fibre varies from 5 and 9 in the mouse and rat respectively $[59,74]$ to over 20 in larger species, such as the pig [86]. Prior to the onset of secondary myogenesis, the diameters of the primary myotubes increase twofold, whereas they later increase in size by elongation [54]. The kinetics of appearance of these two populations vary according to the maturity of the different species (Tab. II). Robelin et al. [72] suggest that this chronology is a function of the gestation length and animal weight at birth.

It is generally believed that primary fibres mature to slow type I fibres in the adult, however, in entirely fast muscles they give rise to fast fibres. The secondary fibres mostly mature to fast fibres in fast muscles and to either fast or slow fibres in the mixed muscles $[46,63]$.

The existence of a third generation of fibres has been described in the sheep [100], pig [46, 53], human [21] and bovine [23]. These cells exhibit a small diameter [26, $52]$, and usually express developmental MHC isoforms [46]. When first formed, they are closely associated with secondary myotubes like newly formed secondary myotubes with primary myotubes [21]. They are observed at about $40 \%$ of the gestation period in bovines, sheep and humans [21, 23, 100] (Tab. II), and around birth in pigs. They only exist in large animals where they could be part of the mechanisms leading to the larger muscle mass.

\subsection{Total number of fibres}

In most species of terrestrial vertebrates, particularly in birds and mammals, the total number of fibres (TNF) is fixed before hatching or birth. This is unlike in some large species of fish (trout for example) in which hyperplasia continues during the postnatal life [85]. In bovines, TNF is fixed
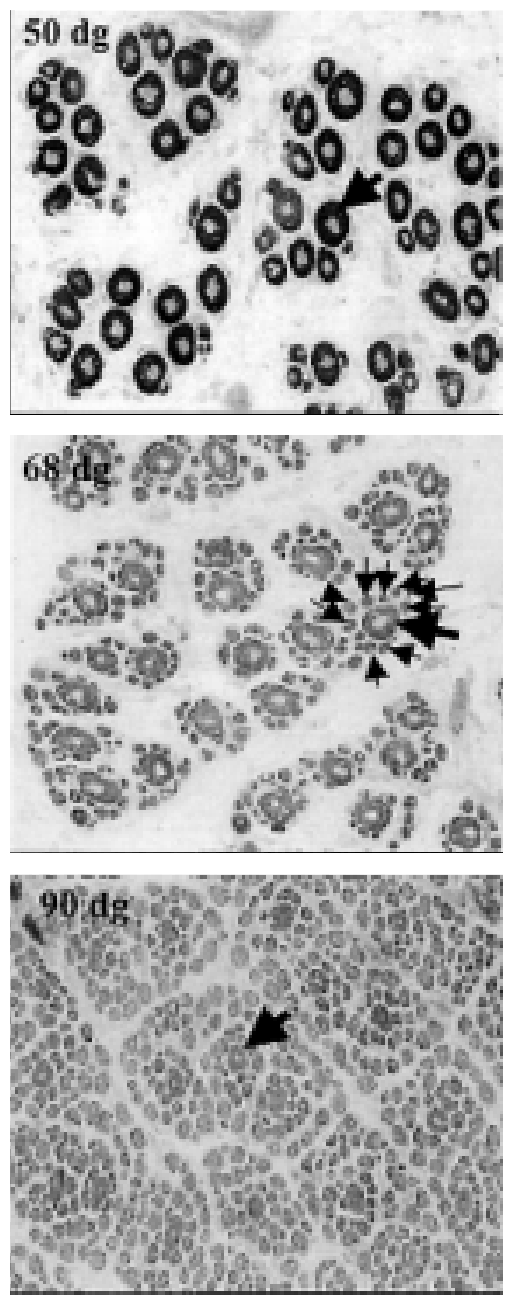

Figure 6. Myogenesis in pig red semitendinosus muscle, Lefaucheur et al. [46]. ATPase $\mathrm{pH} 4.35$. White arrow: primary generation, black arrows: secondary generation. 
Table II. Stage of appearance of the different generations of myogenic cells in various species.

\begin{tabular}{lrrcc}
\hline Generations & Primary & Secondary & Tertiary & References \\
\hline Poultry & $3-7 \mathrm{df}$ & $8-16 \mathrm{df}$ & - & Bandman and Rosser [4] \\
Pig & $35 \mathrm{df}$ & $55 \mathrm{df}$ & 0 to $15 \mathrm{dpn}$ & Lefaucheur et al. [46] \\
Sheep & $32 \mathrm{df}$ & $38 \mathrm{df}$ & $62-76 \mathrm{df}$ & Wilson et al. [100] \\
Bovine & $60 \mathrm{df}$ & $90 \mathrm{df}$ & $110 \mathrm{df}$ & Gagnière et al. [29] \\
Human & $56 \mathrm{df}$ & $90 \mathrm{df}$ & $110-120 \mathrm{df}$ & Draeger et al. [21] \\
\hline
\end{tabular}

df: days of foetal life, dpn: days of postnatal life.

from the end of the second third of gestation (180 days) [29, 62] and in pigs by $80 \%$ of gestation [99]. This suggests that the third generation of fibres which appears later is not quantitatively important in these species. In less mature species such as the rabbit [58] TNF is definitively determined during the first month after birth. In birds, it is generally believed to be established before hatching [68]. There are, however, some exceptions to this rule. For example, some myofibre hyperplasia has been observed in the turkey ALD muscle at 15 weeks of age in a highly muscled industrial genotype [15].

Different works have suggested that the number of primary myofibres is under genetic control in pigs [87] and in bovines [20]. On the contrary, the number of secondary fibres would be more under epigenetic control such as maternal nutrition for the mammalian species. Indeed, undernutrition of pregnant sows leads to offsprings with fewer secondary fibres in their muscles, but no alteration of primary fibres [24]. Low birth weight due to multiple offspring in the pig is also associated with a lower number of secondary fibres [35]. On the contrary, over-nutrition of the sow between 25 and 50 days of gestation [25] or injection of growth hormone between 10 and 24 days of gestation [66] increases the TNF. Therefore, the very early stage of gestation seems to be particularly critical with regards to the nutritional influences on the determination of TNF. The effects of a high nutritional level may involve an increase and/or a prolongation of myoblasts proliferation.
Recent data have shown that the growth factor, Myostatin, a member of the TGF beta super-family responsible for the doublemuscled genotype in bovines, is a negative regulator of TNF [44].

In birds and mammals, the large postnatal increase in muscle mass is achieved by the hypertrophy of the existing fibres due to the fusion of satellite cells with the fibres [32]. These cells are present as a distinct population at least as early as the mid foetal stages of development [28, 37]. In the neonate, they proliferate actively, adding nuclei to fibres [57], while in the adult, they are mitotically quiescent and only become active in response to an insult or injury to the muscle (see review in [12]). They can be distinguished from other myoblasts by their behaviour in cell culture: they require longer periods of time before entering the cell cycle. Whether satellite cells differ between muscle fibres of different types is not clear and could depend on the species.

\subsection{Contractile differentiation}

At birth, the primary and secondary generations of fibres contain developmental MHC (emb, foet, a-cardiac) which are progressively replaced by adult MHC. Most primary fibres express the slow MHC very early during gestation, while the secondary fibres only express it at the end of gestation [16].

In bovine muscle (Fig. 7), the cell population consists only in primary myotubes up 


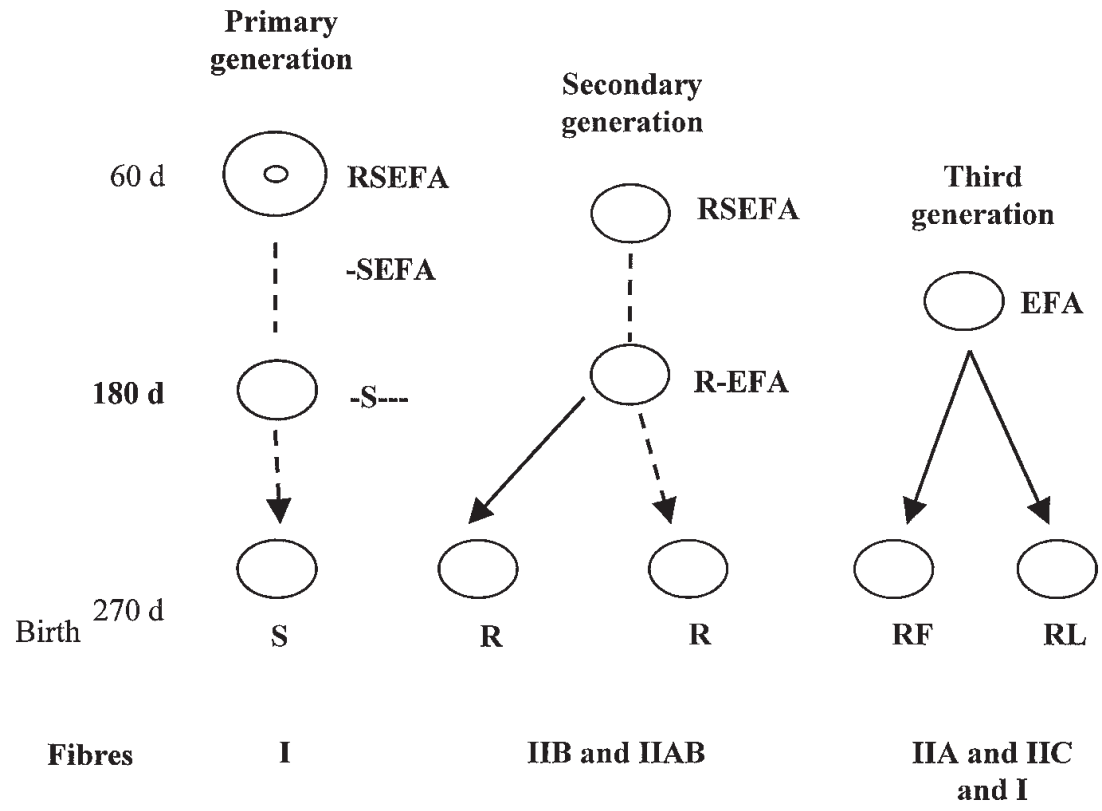

Figure 7. Schematic contractile differentiation of myofibres in bovinemuscle, Picard et al. [62], Gagnière et al. [29]. R: Fast MHC, S: Slow MHC, E: Embryonic MHC, F: Fœtal MHC, A: cardiac MHC.

to 60 days of gestation [71]. First they express slow, fast, emb, foet, and alpha cardiac MHC and from 180 days of gestation, they only express the slow MHC I isoform characteristic of the type I fibres $[62,72]$. In totally fast muscle, they revert to the fast phenotype through type IIC fibres [64]. Secondary fibres when they appear also express slow, fast, emb, foet and alpha cardiac MHC. Most of them subsequently develop into type II fibres, while a few of them also develop into type I fibres [62]. At the same time, emb, foet and alpha cardiac MHC decrease and the proportion of adult MHC (I, IIa and IIx) increases $[62,72]$ so that developmental MHC are completely replaced by adult isoforms by the end of gestation (Fig. 7). Porcine muscle exhibits a highly organised pattern and a unique distribution of fibres consisting in clusters of slow type I fibres surrounded by fast type II fibres (rosette) since foetal life [46]. In this species, primary myotubes initially express emb, foet and slow type I MHC (Fig. 8). They subsequently mature to type I fibres in most muscles, but can also give rise to fast type II fibres in pure fast-twitch muscles, such as the superficial white portion of the semitendinosus [46]. Secondary fibres begin to appear at 50-55 days of gestation and also express emb and foet MHC during the foetal period. However, unlike primary myotubes, they do not express type I MHC until late gestation. Perinatally, a subpopulation of secondary fibres in the direct vicinity of primary myotubes starts to express type I MHC and mature to type I fibres. Some of these fibres transiently express the alpha-cardiac MHC $[46,47]$. Adult fast type IIa MHC is present in some secondary fibres during the foetal period, whereas IIx and IIb appear shortly after birth $[13,14]$. During the first postnatal weeks, secondary fibres which do not express type I MHC mature to either type IIA, IIX or IIB fibres. 


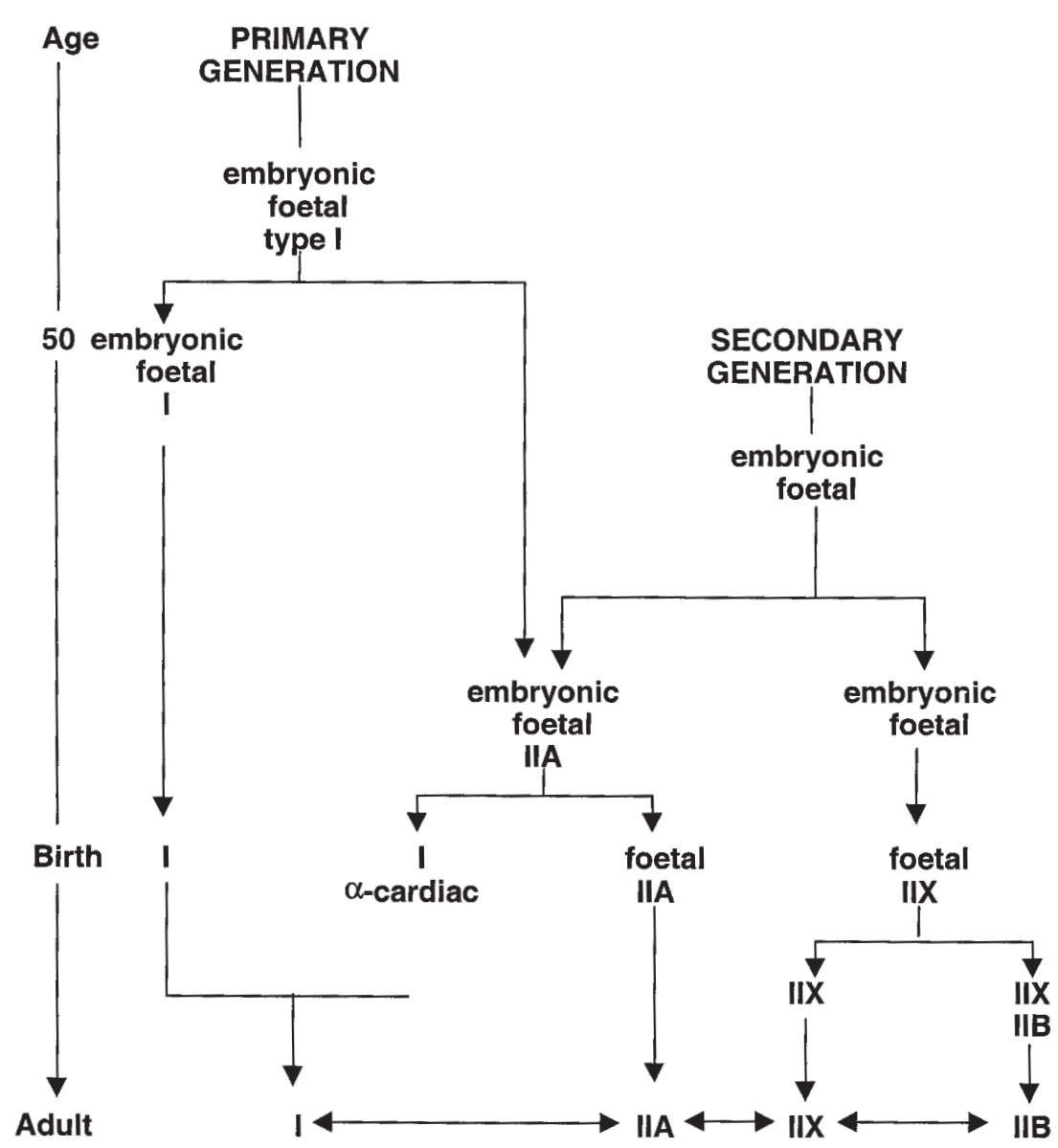

Figure 8. Schematic evolution of fibre type differentiation in developping skeletal muscle of pig based on myosin heavy chain isoform transitions [48].

Recent results in bovine muscle show that foet MHC disappears between $180 \mathrm{df}$ and 21 dpn (Fig. 9a). In other species such as sheep [52], pigs [46], and rabbits [31, 50], foet MHC disappears between $140 \mathrm{df}$ and $28 \mathrm{dpn}, 10$ and $20 \mathrm{dpn}, 20$ and $30 \mathrm{dpn}$, respectively (Tab. III). Fast adult MHC appear at the end of foetal life in bovines (Fig. 9A), sheep muscle and only after birth in pigs and rabbits. For example, all muscles exhibit a slow speed of contraction in the rabbit at birth but ATPase activity increases greatly during the first week. A clear histochemical distinction between IIA and IIB fibres is possible only from 30 days after birth [8, 33]. In the rat, MHC I, IIx and IIa appear before birth and MHC IIb after birth [19]. In bovine muscle, IIA fibres differentiate earlier than IIB fibres [23]. In pig and rabbit muscles, MHC IIa mRNA is expressed earlier than IIx and IIb mRNA $[13,50]$. As mentioned earlier, the situation is different in birds, where muscle fibre contractile typology cannot simply be related to $\mathrm{MHC}$ expression. The slow phenotype is established during the end of the foetal period when MHC expression switches from slow MHC III to slow MHC II (see review 
(A)

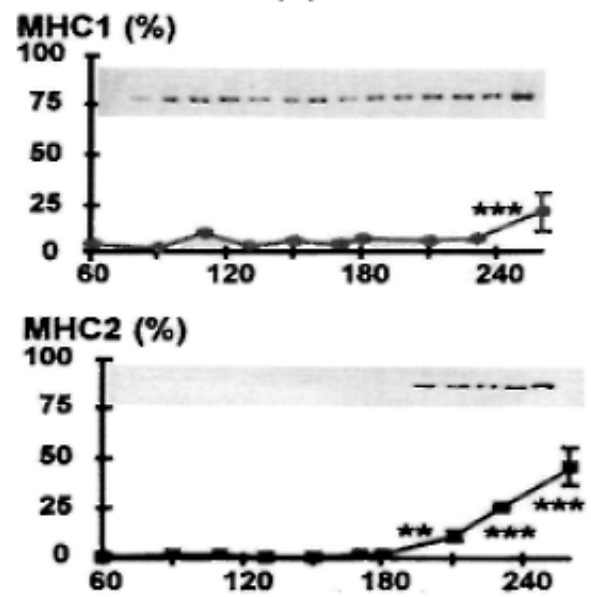

MHC F $(\%)$

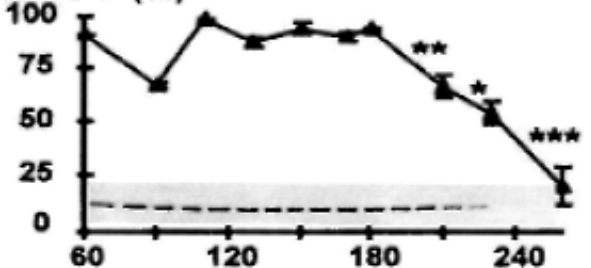

(B)
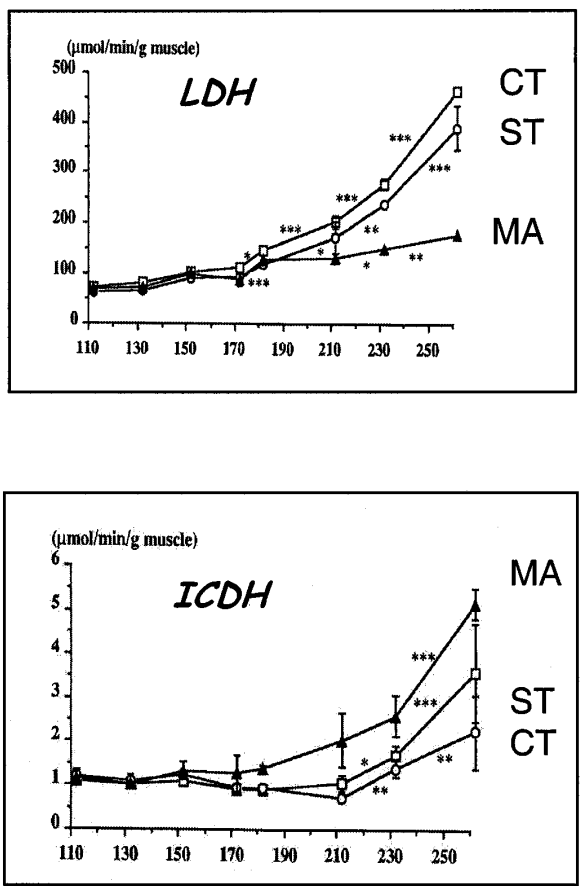

Figure 9. Contractile (A) and metabolic (B) differentiation of bovine muscles during fotal life, Picard et al. [63] et Gagnière et al. [30]. MHC 1: Slow MHC, MHC 2: Fast MHC (IIa, IIx), MHC F: Fœtal MHC, LDH: Lactate dehydrogenase, ICDH: Isocitrate dehydrogenase, MA: Masseter (slow oxidative in adult), CT: Cutaneus trunci (fast glycolytic in adult), ST: Semitendinosus (mixt in adult). $* P<0.05$; ** $P<0.01$; *** $P<0.001$.

in [88]). At the same period, the neonatal isoform disappears in the future fast muscle. However, developmental isoforms can later reappear in fast muscles and only a few of them, among which the Pectoralis Major, finally express the adult fast isoform (see review in [88]). At hatching, fast and slow fibres can be distinguished according to their mATPase activity, but not the IIA and IIB subtypes, which are apparent only at one week of age [68].

The postnatal changes in fibre types vary between species. An increase in the proportion of I fibres was observed during the first 4 or 8 postnatal weeks in sheep [90] and pigs $[18,45]$, respectively. In bovines, this occurs during the last third of gestation $[30,63]$. Overall in mixed muscles of mammals, an increase in type IIB and IIX fibres is observed during postnatal growth together with a decrease of type IIA fibres. In bovines, it seems that this conversion begins soon after birth [63] and is accompanied by an increase in the proportion of hybrid IIAB fibres containing both IIa and IIb MHC [23]. In horses, on the contrary, the proportion of type IIA fibres increases and that of type IIB decreases with age, probably as a consequence of exercise [73]. 
Table III. Stage of disappearance of foetal MHC expression in various species.

\begin{tabular}{lcc}
\hline Species & Stages & References \\
\hline Poultry & 1 week pn & Bandman and Rosser [4] \\
Rat & 0 to $30 \mathrm{dpn}$ & D'Albis et al. [7] \\
Rabbit & 0 to $30 \mathrm{dpn}$ & Gondret et al. [31] \\
Pig & 0 to $15 \mathrm{dpn}$ & Lefaucheur et al. [46] \\
Sheep & $140 \mathrm{df}$ to $28 \mathrm{dpn}$ & Maier et al. [52] \\
Bovine & $180 \mathrm{df}$ to $21 \mathrm{dpn}$ & Duris [23] \\
\hline
\end{tabular}

df: days of foetal life, dpn: days of postnatal life.

Table IV. Stage of increase of glycolytic metabolism in different species.

\begin{tabular}{lcc}
\hline Species & Stages & References \\
\hline Chicken & 0 to $10 \mathrm{dpn}$ & Bacou and Vigneron [2] \\
Rabbit & 0 to $8 \mathrm{wpn}$ & Briand et al. [9] \\
Pig & 0 to $15 \mathrm{dpn}$ & Lefaucheur and Vigneron [45] \\
Bovine & From $210 \mathrm{df}$ & Gagnière et al. [30] \\
\hline
\end{tabular}

df: days of foetal life, dpn: days of postnatal life, wpn: weeks of postnatal life.

\subsection{Metabolic differentiation}

The differentiation of oxidative and glycolytic pathways also depends on the maturity of the species at birth [2]. In rabbits, chickens and pigs, the oxidative metabolism represents the principal source of energy during foetal life. At birth or hatching, all muscles are oxidative, and glycolytic metabolism dramatically increases during the first postnatal weeks (Tab. IV) $[2,8,9$, 45]. Oxidative and glycolytic fibres can be distinguished from 7 to $15 \mathrm{dpn}$ in chickens $[2,71]$, from 10 to $20 \mathrm{dpn}$ in rats [75], from $21 \mathrm{dpn}$ in rabbits [31] and from 21 to $28 \mathrm{dpn}$ in pigs $[18,45]$. In bovines, oxidative and glycolytic enzyme activities increase during the last third of gestation (Fig. 9B) [30, 38]. Fibres can be distinguished on their metabolic properties from 210 days of foetal life [30, 71]. All future type I fibres exhibit an oxidative metabolism from $210 \mathrm{dg}$. For type IIA fibres it increases from the last third of gestation and concerns $100 \%$ of the fibres at 3 weeks pn. The oxidative activity of muscles then decreases between birth up to 9 to 12 months of postnatal life (puberty) in bovine muscle [41], whereas glycolytic metabolism increases. Overall the glycolytic activity increases with growth in all species, but decreases with aging $[9,45,68]$.

\section{CONCLUSION}

This review illustrates that myogenesis is a complex process involving multiple steps and regulation factors. It appears that the general process of myogenesis is similar in the different species (birds, rodents, mammals) involving a succession of at least two generations of myogenic cells. However, the kinetics of muscle fibre development appears different between species depending on their maturity at birth. The precocity of their muscle fibre differentiation can be classified in 
the following order: bovines = humans $>$ sheep > pigs > birds > rabbits > mice and rats. In large mammals such as bovine, sheep and human, the major events of contractile and metabolic differentiation occur during the last third of gestation and are fully achieved just after birth. In these species, foetal life represents a primordial step for muscle maturation. In the less mature species, contractile and metabolic muscle fibre properties mostly differentiate during the first two postnatal weeks in pigs or the first postnatal month in rodents and birds.

For farm animal producers, the knowledge of the accurate kinetics of muscle fibre development is of prime importance to identify the key stages of myogenesis involved in each species. The understanding of this dynamic process may permit to improve breeding conditions and selection criteria necessary to meet the challenge of simultaneously optimising meat quality and efficiency of muscle growth.

\section{REFERENCES}

[1] Ashmore C.R., Doerr L., Comparative aspects of muscle fiber types in different species, Exp. Neurol. 31 (1971) 408-418.

[2] Bacou F., Vigneron P., Évolution périnatale des voies métaboliques glycolytiques et oxydatives de divers types de muscles squelettiques du lapin et du poulet, Ann. Biol. Anim. Biochim. Biophys. 16 (1976) 675-686.

[3] Bandman E., Contractile protein isoforms in muscle development, Dev. Biol. 154 (1992) 273-283.

[4] Bandman E., Rosser B.W., Evolutionary significance of myosin heavy chain heterogeneity in birds, Microsc. Res. Tech. 50 (2000) 473-491.

[5] Bär A, Pette D., Three fast myosin heavy chains in adult rat skeletal muscle, FEBS Lett. 235 (1988) 153-155.

[6] Barnard R.J., Edgerton V.R., Furukawa T., Peter J.B., Histochemical, biochemical and contractile properties of red, white and intermediate fibres, Am. J. Physiol. 220 (1971) 410-414.

[7] Bredman J.J., Weijs W., Moorman A.F., Presence of cardiac a-myosin correlates with histochemical myosin $\mathrm{Ca} 2+$ ATPase activity in rab bit masseter muscle, Histochem. J. 24 (1991) 260-265.
[8] Briand M., Talmant A., Briand Y., Monin G. Durand R., Metabolic types in the sheep. II. Lactate dehydrogenase activity and LDH isozyme distribution, Eur. J. Appl. Physiol. 46 (1981) 359-365.

[9] Briand M., Boisonnet G., Laplace-Marieze V. Briand Y., Metabolic and contractile differentiation of rabbit muscles during growth, Int. J. Biochem. 25 (1993) 1881-1887.

[10] Brooke M.H., Kaiser K.K., Muscle fiber types: how many and what kind?, Arch. Neurol. 23 (1970) 369-379.

[11] Buckingham M., Skeletal muscle formation in vertebrates, Curr. Opin. Genet. Dev. 11 (2001) 440-448.

[12] Campion D.R., The muscle satellite cell: review, Int. Rev. Cytol. 87 (1984) 225-251.

[13] Chang K.C., Fernandes K., Dauncey M.J., Molecular characterization of a developmentally regulated porcine skeletal myosin heavy chain gene and its 5' regulatory region, J. Cell Sci. 108 (1995) 1779-1789.

[14] Chang K.C., Fernandes K., Developmental expression and 5' end cDNA cloning of the porcine $2 \mathrm{x}$ and $2 \mathrm{~b}$ myosin heavy chain genes, DNA Cell Biol. 16 (1997) 1429-1437.

[15] Cherel Y., Hurtrel M., Gardahaut M.F., Merly F., Magras-Resch C., Fontaine-Perus J., Wyers M. Comparison of postnatal development of anterior latissimus dorsi (ALD) muscle in heavy- and light-weight strains of turkey (Meleagris gallopavo), Growth Dev. Aging 58 (1994) 157-165.

[16] Cho M.S., Hughes M., Karsh-Mirzachi I., Travis M., Leinwand L.A., Blau H.M., Fast myosin heavy chains expressed in secondary mammalian muscle fibres at the time of their inception, J. Cell Biol. 107 (1994) 2361-2371.

[17] D'Albis A., Janmot C., Béchet J.J., Comparison of myosins from masseter muscle of adult rat, mouse and guinea-pig. Persistence of neonatal type isoforms in the murine muscle, Eur. J. Biochem. 156 (1986) 291-296.

[18] Davies AS., Postnatal changes in the histochemical fibre types of porcine skeletal muscle, J. Anat. 113 (1972) 213-240.

[19] DeNardi C., Ausoni S., Moretti P., Gorza L. Velleca M., Buckingham M., Schiaffino S., Type 2X-myosin heavy chain is coded by a muscle fiber type-specific and developmentally regulated gene, J. Cell Biol. 123 (1993) 823-835.

[20] Deveaux V., Cassar-Malek I., Picard B., Comparison of contractile characteristics of muscle from holstein and double-muscles belgian blue foetuses, Comp. Biochem. Physiol. 131 (2001) 21-29.

[21] Draeger A., Weeds A.G., Fitzsimons R.B., Primary, secondary and tertiary myotubes in the developing skeletal muscle: a new approach to analysis of human myogenesis, J. Neurol. Sci. 81 (1997) 19-43. 
[22] Dubowitz V., A comparative histochemical study of oxidative enzyme and phosphorylase activity in skeletal muscle, Histochemie 2 (1960) 105-117.

[23] Duris M.P., Variabilité génétique de la différenciation musculaire chez le bovin, P.H.D. Université Blaise Pascal, Clermont-Ferrand 1999, p. 154.

[24] Dwyer C.M., Stickland N.C., Sources of variation in myofibre number within and between litters of pigs, Anim. Prod. 52 (1991) 527-533.

[25] Dwyer C.M., Stickland N.C., Fletcher J.M., The influence of maternal nutrition on muscle fiber number development in the porcine foetus and on subsequent postnatal growth, J. Anim. Sci. 72 (1994) 911-917.

[26] Ecob Prince M., Hill M., Brown W., Immunocytochemical demonstration of myosin heavy chain expression in human muscle, J. Neurol. Sci. 91 (1989) 71-78.

[27] Engel W.K., The essentiality of histo- and cytochemical studies in the investigation of neuromuscular disease, Neurology 12 (1962) 778-784.

[28] Feldman J.L., Stockdale F.E., Temporal appearance of satellite cells during myogenesis, Dev. Biol. 153 (1992) 217-226.

[29] Gagnière H., Picard B., Geay Y., Contractile differentiation of fœtal cattle muscles: intermuscular variability, Reprod. Nutr. Dev. 39 (1999) 637-655.

[30] Gagnière H., Picard B., Jurie C., Geay Y., Comparison of foetal metabolic differentiation in three cattle muscles, Reprod. Nutr. Dev. 39 (1999) 105-112.

[31] Gondret F., Lefaucheur L., Dalbis A., Bonneau M., Myosin isoform transitions in four rabbit muscles during postnatal growth, J. Muscle Res. Cell Motil. 17 (1996) 657-667.

[32] Grounds M.D., Towards understanding skeletal muscle regeneration, Pathol. Res. Pract. 187 (1991) 1-22.

[33] Guth H.L. and Samaha F.J., Erroneous interpretations which may result from application of the myofibrillar ATPase histochemical procedure to developing muscle, Exp. Neurol. 34 (1972) 465-475.

[34] Hämäläinen N., Pette D., Patterns of myosin isoforms in mammalian skeletal muscle fibres, Microsc. Res. Tech. 30 (1995) 381-389.

[35] Handel S.E., Stickland N.C., Muscle cellularity and birth weight, Anim. Prod. 44 (1987) 311-317.

[36] Harris A.J., Fitzsimons R.B., Mac Ewan J.C., Neural control of sequence of expression of myosin heavy chain isoforms in foetal mammalian muscles, Development 107 (1989) 751-769.
[37] Hartley R.S., Bandman E., Yablonkareuveni Z., Skeletal muscle satellite cells appear during late chicken embryogenesis, Dev. Biol. 153 (1992) 206-216.

[38] Hocquette J.F., Piot C., Jurie C., Picard B., Metabolic differentiation of bovine cardiac and skeletal muscles during fotal development. Proceed. of International Congress of Myology, Nice, France, 2000, p. 85.

[39] Hoh J.F.Y., Hughes S., Hale P.T., Fitzsimons R.B., Immunocytochemical and electrophoretic analyses of changes in myosin gene expression in cat limb fast and slow muscles during postnatal development, J. Muscle Res. Cell Motil. 9 (1988) 30-47.

[40] Hughes S.M., Taylor J.M., Tapscott S.J., Gurley C.M., Carter W.J., Peterson C.A., Selective accumulation of myoD and myogenin mRNAs in fast and slow adult skeletal muscles is controlled by innervation and hormones, Development 118 (1993) 1137-1147.

[41] Jurie C., Robelin J., Picard B., Geay Y., Postnatal changes in the biological characteristics of semitendinosus muscle in male Limousin cattle, Meat Sci. 41 (1995) 125-135.

[42] Klitgaard H., Zhou M., Schiaffino S., Betto R., Salviati G., Saltin B., Ageing alters myosin heavy chain composition of single fibres from human skeletal muscle, Acta Physiol. Scand. 140 (1990) 55-62.

[43] Klont R.E., Brocks L., Eikelenboom G., Muscle fiber type and meat quality, Meat Sci. 49 Suppl. 1 (1998) 219-229.

[44] Lee S.J., McPherron A., Myostatin and the control of the skeletal mass, Genet. Dev. 9 (1999) 604-607.

[45] Lefaucheur L., Vigneron P., Post-natal changes in some histochemical and enzymatic characteristics of three pig muscles, Meat Sci. 16 (1986) 199-216.

[46] Lefaucheur L., Edom F., Ecolan P., ButlerBrowne G.S., Pattern of muscle fiber type formation in the pig, Dev. Dyn. 203 (1995) 27-41.

[47] Lefaucheur L., Hoffman R., Okamura C., Gerrard D., Leger J.J., Rubinstein N., Kelly A., Transitory expression of alpha cardiac myosin heavy chain in a subpopulation of secondary generation muscle fibres in the pig, Dev. Dyn. 210 (1997) 106-116.

[48] Lefaucheur L., Hoffman R.K., Gerrard D.E., Okamura C.S., Rubinstein N., Kelly A., Evidence for three adult fast myosin heavy chain isoforms in type II skeletal muscle fibres in pigs, J. Anim. Sci. 76 (1998) 1584-1593.

[49] Leinwand L.A., Fournier R.E.K., Nadal-Ginard B., Shows T.B., Multiple family for sarcomeric myosin heavy chain in mouse and human DNA localization on a single chromosome, Science 221 (1983) 766-769. 
[50] Mac Koy G., Leger M.E., Bacou F., Goldspink G., Differential expression of myosin heavy chain mRNA and protein isoforms in four functionally diverse rabbit skeletal muscles during pre- and postnatal development, Dev. Dyn. 211 (1998) 193-203.

[51] Maier A., Gambke B., Peke D., Immunohistochemical demonstration of embryonic myosin heavy chains in adult mammalian intrafusa fibres, Histochemistry 88 (1988) 267-271.

[52] Maier A., Mac Ewan J.C., Dodds K.G., Fischman D.A., Fitzmons R.B., Harris A.J., Myosin heavy chain composition of single fibres and their origins and distribution in developing fascicles of sheep tibialis cranialis muscles, J. Muscle Res. Cell Motil. 13 (1992) 551-572.

[53] Mascarello J., Stechinni M.L., Rowlerson A. Ballochi E., Tertiary myotubes in postnata growing pig muscle detected by their myosin isoform composition, Anim. Sci. 70 (1992) 1806-1813.

[54] Mc Lennan I.S., Neurogenic and myogenic reg ulation of skeletal muscle formation: A critical re-evaluation, Prog. Neurobiol. 44 (1994) 119-140.

[55] Monin G., Evolution post-mortem du tissu musculaire et conséquences sur les qualités de la viande de porc, J. Rech. Porcine Fr. 20 (1988) 201-214.

[56] Moore L.A., Tidyman W.E., Arrizubieta M.J. Bandman E., Gene conversion within the skeletal myosin multigene family, J. Mol. Biol. 223 (1992) 383-387.

[57] Moss F.P., Leblond C.P., Satellite cells as the source of nuclei in muscles of growing rats, Anat. Rec. 170 (1971) 421-436.

[58] Nougues J., Étude de l'évolution du nombre des fibres musculaires au cours de la croissance postnatale du muscle chez le lapin, C.R. Soc. Biol. Montpellier 166 (1972) 165-172.

[59] Ontell M., Bourke D., Hughes D., Cytoarchitecture of the foetal murine soleus muscle, Am J. Anat. 181 (1988) 267-278.

[60] Pedroso-Domelloff F., Eriksson P.O., ButlerBrowne G.S., Thornell L.E., Expression of $\mathrm{x}$ cardiac myosin heavy chain in mammalian skeletal muscle, Experimentia 48 (1992) 491-494.

[61] Peter J.B., Barnard R.J., Edgerton V.R., Gillespie C.A., Stemple K.E., Metabolic profiles of three fiber types of skeletal muscle in guinea pigs an rabbits, Biochemistry 11 (1972) 2627-2633

[62] Picard B., Robelin J., Pons F., Geay Y., Comparison of the foetal development of fiber types in four bovine muscles, J. Muscle Res. Cel Motil. 15 (1994) 473-486.

[63] Picard B., Gagnière H., Robelin J., Geay Y. Comparison of the foetal development of muscle in normal and double-muscled cattle, J. Muscle Res. Cell Motil. 16 (1995) 629-639.
[64] Picard B., Gagnière H., Geay Y., Contractile differentiation of bovine Masseter muscle, Basic Appl. Myol. 6 (1996) 361-372.

[65] Picard B., Duris M.P., Jurie C., Classification of bovine muscle fibres by different histochemical techniques, Histochem. J. 30 (1998) 473-479.

[66] Rehfeldt C., Fiedler I., Weikard R., Kanitz E., Ender K., It is possible to increase skeletal muscle fibre in utero, Biosci. Rep. 13 (1993) 213-220.

[67] Rehfeldt C., Fiedler I., Dietl G., Ender K., Myogenesis and postnatal skeletal muscle cell growth as influenced by selection, Livest. Prod. Sci. 66 (2000) 177-188.

[68] Rémignon H., Gardahaut M.-F., Marche G., Ricard F.-H., Selection for rapid growth increases the number and the size of muscles fibres without changing their typing in chickens, J. Muscle Res. Cell Motil. 16 (1995) 95-102.

[69] Renand G., Picard B., Touraille C., Berge P., Lepetit J., Relationship between muscle characteristics and meat quality traits of young Charolais bulls, Meat Sci. 59 (2001) 49-60.

[70] Rivero J.L.L., Fast myosin heavy chain isoform in horse skeletal muscle: an immunohistochemical and electrophoretic study, Pferdeilkunde 12 (1996) 523-527.

[71] Robelin J., Lacourt A., Béchet D., Ferrara M Briand Y., Geay Y., Muscle differentiation in the bovine foetus: a histological and histochemical approach, Growth Dev. Aging 55 (1991) 151-160.

[72] Robelin J., Picard B., Listrat A., Jurie C. Barboiron C., Pons F., Geay Y., Myosin expression in Semitendinosus muscle during foetal development of cattle: immunocytochemical and electrophoretic analyses, Reprod. Nutr. Dev. 33 (1993) 25-41.

[73] Roneus M., Muscle characteristics in Standardbreds of different ages and sexes, Equine Vet. J. 25 (1993) 143-146.

[74] Ross J.J., Duxson M.J., Harris A.J., Formation of primary and secondary myotubes in rat lumbrical muscles, Development 100 (1987) 383-394.

[75] Rubinstein N.A., Kelly A.M., Development of muscle fiber specialization in the rat hindlimb, J. Cell. Biol. 90 (1981) 128-144.

[76] Santander R.G., Toledo Lobo M.V., Martinez Alonso F.J. and Martinez Cuadrado G., Fusion mechanism of the myoblasts in the myotome of the chick embryo, Histol. Histopath. 8 (1993) 471-490.

[77] Sassoon D.A., Myogenic regulatory factors: dissecting their role and regulation during vertebrate embryogenesis, Dev. Biol. 156 (1993) $11-23$. 
[78] Schiaffino S., Gorza L., Sartore S., Saggin L. Ausoni S., Vianello M., Gundersen K., Lomo T., Three myosin heavy chain isoforms in type 2 skeletal muscle fibres, J. Muscle Res. Cell Motil 10 (1989) 197-205.

[79] Schiaffino S., Reggiani C., Molecular diversity of myofibrillar proteins: gene regulation and functional significance, Physiol. Rev. 76 (1996) 371-423.

[80] Shrager J.B., Desjardins P.R., Burkman J.M. Human skeletal myosin heavy chain genes are tightly linked in the order embryonic-IIa-IId/ X-IIb-perinatal-extraocular, J. Muscle Res. Cell. Motil. 21 (2000) 345-355.

[81] Smerdu V., Karsch-Mizrachi I., Campione M., Leinwand L., Schiaffino S., Type IIx myosin heavy chain transcripts are expressed in type Ilb fibres of human skeletal muscle, Am. J. Physiol. 267 (1994) 1723-1728.

[82] Soussi-Yanicostas N., L'ontogenèse musculaire : de l'induction mésodermique à la formation du sarcomère, Bull. Inst. Pasteur 89 (1991) 255-295.

[83] Stäl P., Eriksson P.O., Schiaffino S., ButlerBrowne G.S., Thornell L.E., Differences in myosin composition between human oro-facial, masticatory and limb muscles: enzyme, immunohisto and biochemical studies, J. Muscle Res. Cell Motil. 15 (1994) 517-534.

[84] Staron R.S., Pette D., The multiplicity of myosin light and heavy chain combinations in muscle fibres, The Dynamics State of muscle, Pette D. W. de G de Gruyter (Ed.), 1990, pp. 315-328.

[85] Stickland N.C., Growth and development of muscle fibres in the rainbow trout, J. Anat. 137 (1983) 323-333.

[86] Stickland N.C., Handel S.E., The numbers and types of muscle fibres in large and small breeds of pigs, J. Anat. 147 (1986) 181-189.

[87] Stickland N.C., Demirtas B., Clelland A.K., Ashton C., Genetic and nutritional influence on muscle growth in farm animals, Comp. Biochem. Physiol. A 126 (2000) 141.

[88] Stockdale F.E., Miller J.B., The cellular basis of myosin heavy chain isoform during development of avian skeletal muscles, Dev. Biol. 123 (1987) 1-9.

[89] Stockdale F.E., Myogenic cell lineages, Dev. Biol. 154 (1992) 284-298.

[90] Suzuki A., Cassens R.G., A histochemical study of myofiber types in the serratus ventralis thoracis muscle of sheep during growth, J. Anim. Sci. 56 (1983) 1447-1458.

[91] Talmadge R.J., Roy R.R., Edgerton R., Prominence of myosin heavy chain hybrid fibres in soleus muscle of spinal cord-transected rat, J. Appl. Physiol. 78 (1995) 1256-1265.

[92] Tanabe R., Muroya S., Chikuni K., Sequencing of the $2 \mathrm{a}, 2 \mathrm{x}$, and slow isoforms of the bovine myosin heavy chain and the different expression among muscles, Mamm. Genome 9 (1998) 1056-1058

[93] Termin A., Staron R.S., Pette D., Myosin heavy chain isoforms in histochemically defined fiber types of rat muscle, Histochemie 92 (1989) 453-457.

[94] Termin A., Staron R.S., Pette D., Myosin heavy chain isoforms in single fibres of transforming rat muscle, The dynamic State of muscle, Pette D., Ed. Walter de Gruyter, Berlin, 1990, pp. 464-472.

[95] Valin C., Différenciation du tissu musculaire. Conséquences technologiques pour la filière viande, Reprod. Nutr. Dev. 28 (1988) 845-856.

[96] Weiss A., Mcdonough D., Wertman B., Acakposatchivi L., Montgomery K., Kucherlapati T., Leinwand L., Krauter K., Organization of human and mouse skeletal myosin heavy chain gene clusters is highly conserved, Proc. Natl. Acad. Sci. USA 96 (1999) 2958-2963.

[97] Weydert A., Daubas P., Lazaridis I., Barton P., Garner I., Leader D.P., Bonhomme F., Catalan L., Simon D., Guenet J.L., Gros F., Buckingham M., Genes for skeletal muscle myosin heavy chains are clustered and are not located on the same mouse chromosome as alpha-cardiac myosin heavy chain gene, Proc. Natl. Acad. Sci. USA 82 (1985) 7183-7187.

[98] Wieczorek D.F., Periasamy M., Butler-Browne G.S., Whale R.S., Nadal-Ginard B., Co-expression of multiple myosin heavy chain genes in addition to a tissue-specific one in extraocular musculature, J. Cell Biol. 101 (1985) 618-629.

[99] Wigmore P.M., Stickland N.C., Muscle development in large and small pig foetuses, J. Anat. 137 (1983) 235-245.

[100] Wilson S.J., Mc Ewan J.C., Sheard P.W., Harris A.J., Early stages of myogenesis in a large mammals: formation of successive generations of myotubes in sheep tibialis muscle, J. Muscle Res. Cell Motil. 13 (1992) 534-550. 